\title{
SOBRE LA CONSTITUCIÓN DEL ESTADO CONSTITUCIONAL *
}

\author{
Josep Aguiló Regla \\ Universidad de Alicante
}

\section{Introducción}

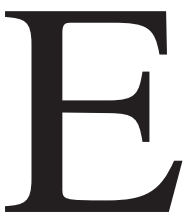

1 propósito de este trabajo es introducir algunas reflexiones sobre el papel que la constitución juega como fuente del Derecho en los llamados Estados constitucionales. Para ello, en primer lugar, me propongo hacer una breve presentación de lo que podríamos llamar la doctrina estándar de las fuentes del Derecho construida desde los parámetros del normativismo. Una de las claves de dicha presentación consistirá en distinguir entre el problema interno y el problema externo de la doctrina de las fuentes. Ello permitirá mostrar la relevancia de la noción de constitución para la teoría del Derecho, pues la constitución acabará operando como el punto de conexión, la bisagra, entre uno y otro problema. A partir de ahí, en segundo lugar, voy a tratar de aislar y de presentar tres conceptos diferentes (aunque no excluyentes) de constitución, a saber, la constitución del positivismo normativista, la constitución formal y la constitución del constitucionalismo. La relevancia de estos tres conceptos de constitución vendrá dada por lo que será una de las tesis principales del trabajo: que todos ellos son necesarios para poder dar cuenta de esa realidad jurídico-política que llamamos «Estados constitucionales». Finalmente, me propongo exponer dos modelos de relación entre constitución regulativa y orden jurídico, en los Estados constitucionales, que conforman, me parece, las dos concepciones dominantes sobre la constitución como fuente del Derecho: en el primero, los deberes incorporados en la constitución se verán como deberes cerrados que imponen límites negativos a la ac-

\footnotetext{
* Este artículo reproduce con algunas modificaciones no sólo de detalle la ponencia titulada «La constitución como fuente del Derecho» que fue presentada al «X Seminario Internacional de Teoría y Filosofía del Derecho» (celebrado en Vaquerías en septiembre de 2001 y organizado por la Universidad Nacional de Córdoba -Argentina-) y al «Primer Congreso Internacional de Teoría del Derecho» (celebrado en Bogotá los días 14, 15 y 16 de marzo de 2002 y organizado por la Universidad Nacional de Colombia).
} 
ción estatal y al contenido del orden jurídico y cuyo cumplimiento requiere centralmente respeto y aplicación de lo prescrito por la constitución; en el segundo, los deberes constitucionales se interpretarán como deberes abiertos que ordenan un cierto modelo de acción estatal y un cierto proyecto de orden jurídico y cuyo cumplimiento requiere centralmente desarrollo y deliberación. La oposición entre estos dos modelos de concepción constitucional no es en realidad otra cosa que una proyección de la oposición general en la concepción del Derecho entre el modelo de las reglas y el modelo de los principios.

\section{El normativismo y la teoría general de las fuentes del Derecho: el problema interno y el problema externo}

Es obvio que la expresión «normativismo» resulta equívoca y que su uso parece requerir muchas precisiones. Sin embargo, aquí no las voy a hacer; voy a tomarla en un sentido muy amplio, de forma que abarque a todas aquellas concepciones del Derecho que, si bien pueden considerar que la fenomenología del Derecho puede resultar extraordinariamente rica y variada (y abarcar sujetos, acciones, hechos, relaciones, instituciones, cosas, actos de fuerza, violencia, prácticas sociales, autoridades...), consideran que el Derecho se objetiva en normas. No presupone, pues, que el Derecho se reduce a normas, sino que las múltiples manifestaciones del Derecho se entienden, explican y enseñan por referencia a normas; de manera que el discurso jurídico es un discurso sobre toda esa rica y variada fenomenología del Derecho objetivada a través de normas.

Es relativamente común comenzar los estudios sobre las fuentes del Derecho poniendo de manifiesto el enredo conceptual que ha caracterizado a la doctrina tradicional de las fuentes; $y$, en no pocas ocasiones, se ha responsabilizado del mismo al uso metafórico de la palabra «fuente», pues -según se dice- habría consentido deslizamientos de significado que estarían en la génesis de la confusión conceptual. Pero, en mi opinión, ello es meramente anecdótico: el enredo conceptual es más bien el producto de la discusión entremezclada de dos problemas diferentes, aunque no independientes entre sí; y, por tanto, el orden conceptual se restablece distinguiendo lo que podríamos llamar el problema interno de la doctrina de las fuentes y el problema externo de la misma ${ }^{1}$.

El problema interno de la doctrina de las fuentes del Derecho no es otro que el del origen de las normas jurídicas. Para el normativismo este proble-

\footnotetext{
${ }^{1} \mathrm{El}$ desarrollo de este apartado viene a ser un resumen de algunas tesis sostenidas en Aguiló Regla, Josep: Teoría general de las fuentes del Derecho (y del orden jurídico), Ariel, Barcelona, 2000.
} 
ma desemboca en un tipo de discurso que se asemeja mucho a los que generalmente se construyen cuando se trata de dar cuenta de las diferentes instituciones jurídicas; porque las fuentes, en este sentido, no son más que otras tantas instituciones jurídicas con la única especificidad de que versan sobre la producción de normas generales. Desde esta perspectiva, la doctrina de las fuentes presenta pocas peculiaridades en relación con el discurso jurídico en general y en torno a las fuentes puede construirse tanto una dogmática como una teoría general. El estudio de las fuentes como problema interno desemboca siempre en un estudio (bien dogmático, bien teórico) sobre las diversas formas de producir normas jurídicas (esto es, las condiciones de existencia de las normas jurídicas, la validez constitutiva de las normas jurídicas) y del régimen jurídico de las normas producidas (esto es, las condiciones de la validez regulativa y las consecuencias jurídicas que de ella se siguen). Es decir, se estudian categorías teóricas como las fuentesacto, las fuentes-hecho, las normas de origen judicial, las normas implícitas, etc. o bien categorías dogmáticas como la ley, el reglamento, los convenios colectivos de trabajo, los tratados internacionales, la costumbre, la jurisprudencia, etc. Pero en todas ellas se tratará de estudiar, por un lado, las normas jurídicas vistas como el resultado de ciertos procesos y, por otro, el régimen jurídico de las normas producidas vinculado al proceso del que ellas son un resultado (centralmente, la jerarquía).

Desde esta perspectiva, la constitución presenta pocas peculiaridades en relación con las otras fuentes del Derecho; habrá, si se quiere, diferencias de grado, pero no diferencias cualitativas. La constitución es una fuente más; las normas constitucionales son el resultado de un cierto proceso (del proceso constituyente o del de reforma constitucional) y tienen su propio régimen jurídico (su propio lugar dentro de la jerarquía normativa). Obviamente, desde esta perspectiva puede construirse tanto una dogmática como una teoría general de la constitución como fuente del Derecho.

Ahora bien, la teoría de las fuentes del Derecho no es tan «inocente» o «ingenua» como lo anterior pudiera llevar a pensar, pues ella ha jugado un papel central dentro del discurso de la teoría del Derecho. En efecto, la teoría del Derecho normativista, en su tarea de construir un concepto de Derecho adecuado para dar cuenta de la práctica y de la doctrina jurídicas, ha recurrido a la teoría de las fuentes para componer la imagen del Derecho. En realidad, ha tomado tres problemas básicos de la experiencia cotidiana de los juristas (el de la identificación del Derecho, el de la unidad del Derecho y el de la continuidad del Derecho), los ha vinculado con el problema del concepto de Derecho y en gran medida ha recurrido a la teoría de las fuentes para componer la imagen del Derecho. Este recurso a la teoría de las fuentes para construir el concepto de Derecho constituye lo que he llamado 
el problema externo de la teoría de las fuentes: el del límite o el marco del problema interno. Pero vayamos por partes: detengámonos brevemente a explicar esos tres problemas básicos de la experiencia de los juristas, apuntando qué papel se ha atribuido a la teoría de las fuentes en relación con cada uno de ellos y mostrando cómo se ha resuelto generalmente la cuestión del límite o del marco.

Desde el normativismo, el problema de la identificación del Derecho no es otro que el de la identificación de las normas jurídicas. Forma parte de la experiencia básica de todo jurista el dato de que no toda norma socialmente existente es susceptible de ser usada en la resolución de casos jurídicos, sino sólo algunas, las jurídicas. Ello ha llevado a la teoría del Derecho a conceptualizar el Derecho como un conjunto específico de normas; de esta manera el Derecho aparece distinguido de su ambiente. No creo que resulte controvertida la afirmación de que el origen de las normas ha sido uno de los criterios más recurrentes en la determinación de ese conjunto de normas; y ello ha situado inevitablemente a la teoría de las fuentes en el centro de esa imagen del Derecho. Ahora bien, como es sobradamente conocido, la teoría de las fuentes como problema interno (es decir, respondiendo a la cuestión del origen de las normas jurídicas), llevada de forma recursiva a su límite, se muestra impotente. Por ello, la teoría del Derecho ha recurrido a la idea de norma última, suprema o independiente que determina los criterios últimos, supremos o independientes de pertenencia de una norma al conjunto de normas que es el Derecho ${ }^{2}$. Así, si la teoría de las fuentes como cuestión interna (al estudiar los procesos normativos de creación de las normas jurídicas) suministra los criterios no últimos, no supremos o no independientes (derivados) de pertenencia de las normas al conjunto; la teoría de las fuentes como cuestión externa desemboca en la determinación de los criterios últimos, supremos o independientes de pertenencia al conjunto de normas que es el Derecho.

El problema de la unidad del Derecho ha estado también permanentemente presente en la conceptualización del Derecho. En efecto, la idea de conjunto de normas no agota la imagen que los juristas tienen del Derecho, pues ella no es suficiente para dar cuenta de otro aspecto central de su quehacer cotidiano. Todo jurista sabe que la solución de un caso jurídico -aquella a la que se llega al final de un razonamiento jurídico- no es la solución

\footnotetext{
${ }^{2}$ En esta exposición voy a prescindir de bastantes matices internos al normativismo porque me interesa mostrar sobre todo sus rasgos comunes. Pero las nociones de norma última, suprema o independiente no son equivalentes entre sí. Así, por ejemplo, mientras que la noción de norma suprema es claramente intrasistemática, la de norma última es extrasistemática. Además, a su vez, pueden introducirse múltiples diferencias nada despreciables respecto de su naturaleza y función.
} 
según la norma que da cobertura al caso, sino la solución según el Derecho. Las soluciones jurídicas, en este sentido, no tienen la fuerza de la norma usada, sino la fuerza del Derecho. Es decir, todo jurista sabe que al final de un razonamiento jurídico la diversidad de fuentes y de normas se reduce a la unidad del Derecho. Este dato obvio es el que explica la fortuna de las conceptualizaciones del Derecho no sólo como un conjunto de normas, sino como sistema de normas. Pues bien: la teoría de las fuentes del Derecho estudia -como se ha dicho- el régimen jurídico (básicamente la jerarquía) de las normas identificadas; y el régimen jurídico de las normas es una pieza clave en la construcción de la unidad del Derecho. Ello sitúa de nuevo a la teoría de las fuentes en el centro de la imagen del Derecho, en este caso de la imagen sistemática y unitaria del Derecho. Pero la teoría de las fuentes como problema interno (es decir, respondiendo a la cuestión del régimen jurídico de las normas producidas), llevada recursivamente a su límite, se muestra de nuevo impotente. Por ello, la teoría del Derecho ha recurrido también a la idea de norma última, suprema o independiente para dar cuenta de la unidad desde la perspectiva estática del Derecho.

El problema de la continuidad y la dinamicidad del Derecho ha acompañado también de manera recurrente a la conceptualización del Derecho. El Derecho no es sólo un conjunto de normas ni una unidad estática de normas. Forma parte de la experiencia de todo jurista el dato de que las normas jurídicas cambian con relativa frecuencia mientras que el orden jurídico sólo cambia muy excepcionalmente. La teoría de las fuentes como problema interno -al estudiar los procesos de creación de normas jurídicas- se halla una vez más en el centro de la imagen del Derecho, en este caso, de la explicación de la continuidad y la dinamicidad del Derecho. Pero nuevamente dicha teoría, llevada recursivamente al límite, se muestra impotente. Por ello, el normativismo ha recurrido a la noción de norma última, suprema o independiente para explicar esa combinación de permanencia y variabilidad: la permanencia se ha explicado por referencia a ciertas normas últimas y la variabilidad o dinamicidad por referencia a las diversas fuentes.

Estos roles que la teoría de las fuentes ha jugado en la composición de la imagen del Derecho constituyen lo que he llamado el problema externo de la misma. Internamente el discurso sobre las fuentes versa sobre la diversidad en la producción jurídica y el régimen jurídico de las normas producidas; externamente versa sobre la composición de la imagen del Derecho: la identificación, la unidad estática y la continuidad dinámica son tres problemas clásicos de la teoría del Derecho. Pues bien: si se es consciente de ello y de que la respuesta estándar del normativismo ha consistido en remitir estos tres problemas a la idea de norma(s) suprema(s), última(s) o independiente(s), entonces es fácil entender por qué desde el normativismo 
las disputas teóricas a propósito del concepto y la naturaleza del Derecho se han canalizado en gran medida a través de la discusión sobre el concepto y la naturaleza de dicha(s) norma(s) última(s), suprema(s) o independiente(s). No hace falta detenerse ahora a explicar cuáles han sido las concepciones más relevantes al respecto. En este punto, simplemente me interesa llamar la atención sobre lo siguiente. Quien acepte grosso modo parámetros como los anteriores me parece que se ve comprometido a reconocer que la constitución como fuente del Derecho no presenta, en relación con las otras fuentes, tan pocas peculiaridades como, en principio, al haber tomado en consideración sólo la perspectiva interna, pudiera haber parecido. Entre la constitución y las otras fuentes tal vez no haya ya sólo diferencias de grado, sino también diferencias cualitativas; porque, entre otras cosas, desde estos parámetros la constitución se convierte en el punto de conexión entre el problema interno de las fuentes (la diversidad en la producción normativa y el régimen jurídico de las normas producidas) y el problema externo (la construcción de la imagen del Derecho, la respuesta a la pregunta por el concepto y la naturaleza del Derecho - por los componentes y los límites de lo jurídico-). Es decir, la constitución opera como el puente entre la diversidad en la producción normativa, por un lado, y la identificación, la unidad y la permanencia del orden jurídico, por otro. Si se acepta lo anterior entonces es fácil percatarse de que no puede haber mucha distancia entre una concepción del orden jurídico (el concepto y la naturaleza del Derecho) y una concepción de la constitución (el concepto y la naturaleza de la constitución). Si ello es así, entonces la teoría de la constitución se convierte en un fragmento central de la teoría del Derecho y sobre ella se proyectan directamente muchas de las disputas respecto de la naturaleza del Derecho ${ }^{3}$.

\footnotetext{
${ }^{3}$ El planteamiento que trato de hacer está muy próximo al que propone Comanducci [en Comanducci, Paolo: «Modelos e interpretación de la Constitución», en Carbonell, Miguel (Compilador): Teoría de la Constitución. Ensayos escogidos, Porrúa-UNAM, México, 2000, págs. 123 y ss.] en relación con la interpretación de la constitución, aunque creo que los alcances y los propósitos son diferentes. La especificidad de la interpretación de la constitución puede abordarse, por un lado, partiendo de lo que las constituciones tienen en común con las otras fuentes del Derecho (las leyes, los contratos, los actos administrativos, etc.) y que no es otra cosa que todas ellas son textos, documentos normativos. Esta forma de abordar la cuestión coincide básicamente con lo que yo he llamado el problema interno de las fuentes del Derecho y supone que las operaciones del método jurídico (y entre ellas la interpretación) recorren todas las fuentes. Ello desemboca en diferencias de grado entre la constitución y las otras fuentes, pero en nada más. Ahora bien, Comanducci viene a sostener que hay otra forma de abordar la cuestión y que ésa es la que ha seguido la discusión teórica sobre la constitución, donde el planteamiento más bien se invierte. La configuración del objeto constitución es el que condicionará en qué consiste la interpretación; de forma que según qué se entienda por constitución se derivarán diferentes modos de entender la interpretación. Este segundo aspecto de la cuestión coincide con lo que -desde planteamientos más generales- he llamado el problema
} 
Todo lo anterior me parece que no presenta grandes dificultades y que, en consecuencia, resulta fácilmente aceptable. El problema mayor posiblemente radique en que las nociones clave, «normativismo» y «constitución», se han usado de manera muy genérica e imprecisa y ello puede llevar a pensar que lo dicho, si bien es aceptable, no es muy significativo. A continuación, trataré de aislar tres conceptos diferentes de constitución que nos permitirán, me parece, precisar bastante lo anterior.

\section{Algunos conceptos de constitución}

Naturalmente, el catálogo de conceptos de constitución y de concepciones constitucionales es prácticamente infinito y aquí no puedo siquiera hacer un esbozo del mismo. En este punto me interesa simplemente introducir algunos conceptos de constitución que más adelante me permitirán realizar algunas estipulaciones para poder dar cuenta de los llamados Estados constitucionales. Todo el discurso se va a vertebrar en torno a la oposición entre constitución necesaria y constitución contingente; lo que supone oponer aquellos conceptos de constitución que presuponen que todo sistema jurídico-político estable cuenta con una constitución a aquellos otros conceptos que no lo presuponen. La necesariedad será un producto de exigencias metodológicas derivadas de una cierta forma de aprehender los fenómenos jurídicos y políticos; y la contingencia será el producto de tomar en consideración bien algunos hechos, bien algunas exigencias normativas y valorativas.

\subsection{La constitución necesaria: la constitución del positivismo normativista}

De entre los distintos conceptos de constitución necesaria me interesa detenerme exclusivamente en el del positivismo normativista. En términos muy generales puede decirse que el positivismo normativista sostiene que por constitución hay que entender «el conjunto de normas fundamentales de un sistema jurídico-político» ${ }^{4}$. Caracterizar al positivismo jurídico, en general, y al normativista, en particular, es una cuestión compleja que está mucho más allá de los propósitos de este trabajo. Aquí me voy a referir a todo ello con trazos muy gruesos pero espero que significativos. El positivismo

externo de las fuentes del Derecho y que hace que la concepción de la constitución aparezca como un fragmento central de la concepción del Derecho y que afecte a todas las operaciones del método jurídico.

${ }^{4}$ Cfr. Guastini, Riccardo: Teoria e dogmatica delle fonti, Giuffrè, Milán, 1998, págs. 310 y ss. 
jurídico, en general, o el postivismo como enfoque ${ }^{5}$, suele caracterizarse a partir de las dos siguientes tesis: la tesis de las fuentes sociales del Derecho y la tesis de la separación conceptual entre Derecho y moral. La tesis de las fuentes sociales del Derecho, que constituye el elemento empirista o factualista del positivismo, viene a significar grosso modo que el Derecho es un orden social de la conducta y que, como tal, es artificial, no natural; de forma que el Derecho o es orden de la conducta (estabilización de la conducta social) o no es Derecho. Ello supone que el Derecho es un fenómeno social e histórico. La segunda tesis, la de la separación conceptual entre Derecho y moral, que puede verse como un corolario de la tesis de las fuentes sociales o como una tesis independiente, es que la determinación de lo que es el Derecho de una comunidad puede resolverse mediante la observación de hechos sociales complejos, básicamente de conducta social. Por ello, la determinación de lo que es el Derecho de una comunidad puede resolverse al margen de cuestiones valorativas o morales. En cualquier caso, lo que me interesa resaltar ahora es que para que la observación referida pueda tener lugar es condición necesaria la propia vigencia del Derecho, es decir, que se haya producido una cierta estabilización y/o estandarización de las conductas jurídicas y políticas; porque lo que se trata de observar son regularidades de conducta. Eso es lo que está implicado en la idea de que el Derecho o es orden de la conducta social (estabilización de conducta) o no es Derecho.

Ahora bien, lo anterior son las propiedades con las que suele caracterizarse al positivismo jurídico entendido como enfoque. Entendido como teoría, es decir, no ya como enfoque sino como respuesta, pueden distinguirse a su vez dos grandes modelos que son el resultado de interpretar de maneras diferentes las regularidades de conducta observadas: uno es el que podríamos llamar «positivismo predictivista» (que incluiría al realismo jurídico, pero no sólo a él: algunas concepciones imperativistas del Derecho comparten los rasgos aquí tomados como relevantes), y otro, el positivismo normativista. La clave para distinguir entre ellos está en cómo interpretan esas regularidades de conducta y las expectativas que de ellas se derivan. Si ellas permiten emitir simplemente juicios fácticos en términos de probabilidad de conducta; o si, por el contrario, dan lugar a juicios normativos en términos de conducta debida. Pues bien, lo que llamamos positivismo normativista se caracteriza por operar una peculiar combinación de juicios fácticos y normativos; de forma tal que los juicios jurídicos internos son juicios normati-

\footnotetext{
${ }^{5}$ Uso de un modo flexible la distinción bobbiana entre el positivismo como enfoque y como teoría. Cfr. Bobbio, Norberto: El problema del positivismo jurídico (trad. E. Garzón Valdés), Eudeba, Buenos Aires, 1965, cap. 2.
} 
vos, donde las nociones centrales son las de deber y validez, y los juicios jurídicos externos, aquellos que versan sobre los límites de la racionalidad interna, son juicios fácticos relativos a regularidades y expectativas de conducta. En este sentido, el positivismo normativista asume una estructura de razonamiento interno normativo y recursivo y remite a la idea de norma última, suprema o independiente el elemento fáctico o empírico de efectividad del Derecho. Es decir, todo el positivismo normativista ha versado sobre la combinación de los principios de efectividad (o «facticidad») del Derecho y de normatividad (o «validez») del Derecho. No hace falta decir que las discusiones internas a este positivismo han sido múltiples y de lo más variado; sin embargo, aquí me interesa simplemente mostrar lo que serían sus rasgos comunes.

Volvamos ahora a la idea de constitución del positivismo normativista. Pues bien, el positivismo normativista ha operado con un concepto de constitución que vendría a ser el conjunto de normas fundamentales de un sistema jurídico-político. Su carácter de «fundamentales» proviene del hecho de que a ellas se remiten los tres problemas básicos que se han enfrentado a la hora de conceptualizar el Derecho y a los que ya me he referido en el apartado anterior: el de la identificación del Derecho, el de la unidad del Derecho y el de la continuidad del Derecho. Su «fundamentalidad» proviene, en definitiva, de que se trata de normas que no remiten recursivamente a otras normas. La siguiente cita de Kelsen ${ }^{6}$ me parece muy representativa de lo que se trata de expresar:

«A través de las múltiples transformaciones sufridas, la noción de Constitución ha conservado un núcleo permanente: la idea de un principio supremo que determina el orden estatal en su totalidad y la esencia de la comunidad constituida por este orden [...] la Constitución es siempre el fundamento del Estado, la base del ordenamiento jurídico de que se trate. Lo que se entiende ante todo y siempre por Constitución [...] es un principio en el que se expresa jurídicamente el equilibrio de las fuerzas políticas en el momento que se toma en consideración, es la norma que regula la elaboración de las leyes, de las normas generales en ejecución de las cuales se ejerce la actividad de los órganos estatales [...] Esta regla sobre la creación de las normas jurídicas esenciales del Estado, sobre la determinación de los órganos y el procedimiento de la legislación forma la Constitución en el sentido propio, originario y estricto de la palabra. Es la base indispensable de las normas jurídicas que regulan la conducta recíproca de los miembros de la comunidad estatal [...] es decir, la base fundamental del ordenamiento estatal [...] De ahí surge la idea de asegurar a la Constitución la mayor estabilidad posible, diferenciando las normas constitucionales de las normas le-

\footnotetext{
${ }^{6}$ Kelsen, Hans: «La garantía jurisdiccional de la Constitución (La justicia constitucional)» (trad. de Juan Ruiz Manero), en Kelsen, Hans: Escritos sobre la democracia y el socialismo, Debate, Madrid, 1988, págs. 114-115.
} 
gales y sometiendo la revisión de las primeras a un procedimiento especial, que contemple condiciones más difíciles de reunir. Aparece así la distinción entre la forma constitucional y la forma legal ordinaria».

Conviene destacar algunas notas en relación con este concepto de constitución. En primer lugar, su carácter de concepto necesario. Todo sistema jurídico-político positivo (existente, estable) cuenta con un conjunto de normas a las que se remite la identificación, la unidad y la permanencia del mismo. Ello es una consecuencia de las tesis normativistas: el fenómeno jurídico puede ser muy variado y complejo, pero el discurso jurídico se objetiva en normas. En segundo lugar, dicho concepto de constitución opera ex post: una vez que se ha producido la estabilización de las conductas jurídicas y políticas de una comunidad, que se ha generado una práctica jurídica y política, que se puede hablar de expectativas fundadas de conducta, puede determinarse el conjunto de normas que de hecho operan como fundamentales en esa comunidad. O dicho en otras palabras y para evitar la crítica de la circularidad, sólo puede operar una vez que se ha producido una cierta estabilización de las conductas relativas al monopolio de la coacción. Ello no es más que una consecuencia de la tesis de la positividad, pues si no operase ex post se estarían traicionando los propios fundamentos empiristas del positivismo?.

Y finalmente, en tercer lugar, hay que resaltar algo que me parece de una importancia capital. Hablar de constitución en este sentido supone hablar de práctica social, de orden de la conducta, de estabilización de expectativas de

\footnotetext{
${ }^{7}$ Ernesto Garzón Valdés ha estudiado el concepto de estabilidad de los sistemas políticos y lo ha presentado como una propiedad disposicional de los mismos. Así, establece la siguiente definición: «Un determinado sistema político es estable si y sólo si en los casos vinculados con el ejercicio institucionalizado del poder, sean éstos 'normales' o 'límites', tiene la tendencia a reaccionar de forma tal que sus cambios son una explicación eficaz de su 'regla de reconocimiento' y esta tendencia se mantiene durante un lapso significativo desde el punto de vista de su contexto histórico y regional» [Garzón Valdés, E.: El concepto de estabilidad de los sistemas políticos, CEC, Madrid, 1987, pág. 44.]. En mi opinión, este planteamiento presenta el siguiente problema. Como puede observarse, Garzón Valdés usa la regla de reconocimiento hartiana exclusivamente como el criterio conceptual que está en la base de la explicación de la identidad y la unidad de los sistemas políticos (págs. 15-16), pero no de su estabilidad (o perduración a lo largo del tiempo). El planteamiento de Hart obviamente es posible que resulte ambiguo pero, en mi opinión, la caracterización que él hace de la regla de reconocimiento como una regla social aceptada y que por tanto, como reconoce Garzón Valdés, «su constatación es una cuestión eminentemente empírica» (pág. 16), hace que la misma regla de reconocimiento comporte un elemento de explicación de la perduralibidad a lo largo del tiempo de los sistemas jurídico-políticos, es decir, presupone la estabilidad de los mismos. En mi opinión, ello es así porque para que la regla de reconocimiento pueda servir -como dice Garzón Valdés- de criterio para la identificación de un sistema político, ella misma tiene que ser una manifestación de la estabilización de las conductas vinculadas con el ejercicio institucionalizado del poder.
} 
conducta, etc. Por tanto, desde esta perspectiva interpretar la constitución no puede entenderse jamás como la tarea consistente en interpretar una norma en el sentido de una formulación normativa (este concepto de constitución es compatible con el de constitución formal, pero no lo presupone), sino más bien la de interpretar una práctica social con el fin de llegar a determinar la norma o normas que permitan dar cuenta de la misma ${ }^{8}$. Esta tarea reconstructiva enfrenta al positivismo con un dilema que en las últimas décadas ha sido puesto de manifiesto en infinidad de ocasiones. Si el positivismo se mantiene fiel a sus presupuestos empiristas entonces explica satisfactoriamente la socialidad (positividad) del Derecho, pero se muestra impotente a la hora de explicar otra nota que parece consustancial al Derecho cual es la pretensión de normatividad, que el Derecho pretende ser fuente de deberes genuinos. Ello es así, porque de la constatación de hechos sociales no parece que puedan inferirse deberes genuinos, sino sólo deberes entrecomillados o deberes «según». Estas dificultades están en la base del

\footnotetext{
${ }^{8}$ En esta exposición he prescindido de muchos detalles internos al positivismo normativista que resultan, sin duda, relevantes. Obviamente todo lo que se acaba de decir está más próximo a los planteamientos del positivismo hartiano que a los del kelseniano. En ambos encontramos claves para hablar de la constitución necesaria en el sentido de conjunto de normas fundamentales de un sistema jurídico-político, pero entre ellos hay diferencias muy importantes a la hora de dar cuenta del principio de efectividad del Derecho; diferencias que tienen una extraordinaria repercusión en la composición de la imagen del Derecho. Así, por ejemplo, mientras que en los planteamientos de Kelsen la cuestión de la efectividad aparece muy vinculada a la existencia del Estado y a la capacidad de imposición política (la constitución «expresa jurídicamente el equilibrio de las fuerzas políticas»), en los planteamientos hartianos el principio de efectividad se plasma en términos de regla o práctica social. Ello tiene hondas repercusiones pues mientras que para Kelsen el Derecho puede tener cualquier contenido (cualquier contenido es susceptible de ser impuesto), para Hart sólo son viables, estabilizables, susceptibles de ser practicados aquellos que respeten «el contenido mínimo de Derecho Natural». En cualquier caso y más allá de lo anterior, me parece esclarecedor reproducir aquí la conocida crítica de Hart a Kelsen a propósito de las relaciones entre constitución y regla de reconocimiento. Escribe Hart: «La norma básica de Kelsen tiene siempre, en cierto sentido, el mismo contenido; porque ella es simplemente en todos los sistemas jurídicos la regla que dice que debe obedecerse la constitución o a 'quienes establecieron la primera constitución'. Esta apariencia de uniformidad y simplicidad puede ser engañosa. Si una constitución que especifica las varias fuentes de derecho es una realidad viviente en el sentido de que los tribunales y los funcionarios del sistema efectivamente identifican el derecho con arreglo a los criterios que ella suministra, entonces la constitución es aceptada y efectivamente existente. Parece una duplicación innecesaria sugerir que hay otra regla más que dispone que la constitución (o quienes la 'establecieron') ha de ser obedecida. Esto es particularmente claro cuando, como ocurre en el Reino Unido, no hay constitución escrita: aquí parece no haber cabida para la regla 'la constitución debe ser obedecida' como cosa adicional a la regla de que deben usarse ciertos criterios de validez (p. ej. sanción por la Reina en Parlamento) para identificar el derecho. Esta es la regla aceptada y es un factor de confusión hablar de una regla que prescribe la obediencia a ella». Hart, H.L.A.: El concepto de Derecho (trad. de Genaro Carrió), Abeledo-Perrot, Buenos Aires, $2^{\text {a }}$ ed. (reimpresión), 1992, pág. 311.
} 
auge de las teorías del participante (frente a las del observador). Pero a su vez las teorías del participante se enfrentan con un problema básico que hace quebrar los presupuestos empiristas del positivismo, porque las prácticas sociales nunca son tan homogéneas como para poder ser descritas completamente «sin más» y poder ser usadas «como si». Participar en una práctica social no es sólo reproducir conducta, tiene también un componente constructivo de la propia práctica. Y si ello es así, entonces usar normativamente esa práctica (ese conjunto de normas fundamentales) supone necesariamente embarcarse en la tarea de dotarla de sentido. Y esa discusión supone abandonar la observación para entrar de lleno en la participación? . Pero no nos distraigamos de nuestro objetivo. Me interesa ahora, no tanto resaltar las dificultades internas del positivismo, sino más bien retener dos cosas: una, el concepto de constitución como conjunto de normas fundamentales de un sistema jurídico-político estable sólo es determinable ex post; y, dos, no puede cumplir funciones normativas en el sentido de que de ella no pueden inferirse deberes genuinos, es decir, cumple funciones explicativas, no normativas. En este sentido, puede usarse en términos predictivos, pero no justificativos.

\subsection{La constitución contingente: la constitución formal y la constitución del constitucionalismo}

Frente a la noción de constitución necesaria, la de constitución contingente está construida sobre la base de que no todo sistema jurídico-político estable cuenta con una constitución, sino sólo algunos de ellos. Las dos fuentes de contingencia constitucional más importantes son la forma constitucional (no todo sistema jurídico-político estable cuenta con una constitución formal) y los ideales del constitucionalismo político, es decir, el constitucionalismo como ideología (no todo sistema jurídico-político estable cuenta con una constitución en el sentido del constitucionalismo político). La contingencia de la constitución formal es obvia, pues depende de hechos que pueden ocurrir o no; y la contingencia de la constitución del constitucionalismo también, porque los hechos relevantes pueden satisfacer o no sus exigencias normativas y/o valorativas. Detengámonos brevemente en todo ello.

\footnotetext{
${ }^{9}$ Para una exposición de las dificultades de la «tesis de la identificación objetiva del Derecho» y de la distancia entre el Derecho identificado por el participante y el Derecho identificado por el observador, véase Bayón, Juan Carlos: «Partecipanti, osservatori, e identificazione del diritto», en Comanducci, P y Guastini, R (ed): Struttura e dinamica dei sistemi giuridici, Giappichelli, Turín, 1996, págs. 47 y ss.
} 


\subsubsection{La constitución formal}

La idea de constitución formal (o de forma constitucional como opuesta a la idea de forma legal) remite a la noción de constitución rígida ${ }^{10}$. Suele decirse que un sistema jurídico político cuenta con la forma constitucional cuando se dan las dos siguientes condiciones: 1. el conjunto de normas fundamentales de ese sistema jurídico-político se halla codificado; y 2. el procedimiento para la reforma o derogación está fuera del alcance del legislador ordinario; o, lo que es lo mismo, es un procedimiento agravado en relación con el de la legislación ordinaria. De la conjunción de ambas se sigue una tercera y es que 3. la constitución ocupa una jerarquía normativa superior a la ley dentro del sistema de fuentes ${ }^{11}$. La presencia de una constitución formal en el interior de un sistema jurídico-político tiene una trascendencia fundamental. De las múltiples consecuencias que de ello se derivan, voy a resaltar la que me parece más importante y de la que, en realidad, las demás son un corolario. La constitución formal presupone necesariamente una acción deliberada, un momento decisional, un momento «cero». Ello plantea inevitablemente en el interior de ese sistema político el problema de las relaciones entre poder constituyente (llamado a extinguirse) y poder soberano (permanente) ${ }^{12}$. En este sentido, la constitución formal

${ }^{10}$ Bryce, James: Constituciones flexibles y constituciones rígidas (Est. preliminar de Pablo Lucas Verdú), CEC, Madrid, 1988.

${ }^{11}$ Como ha resaltado Víctor Ferreres la rigidez efectiva de una constitución depende de una combinación de exigencias jurídico-formales y de circunstancias políticas. Entre las primeras destaca como factores de los que depende la rigidez los siguientes: a) el número de instituciones políticas cuyo consentimiento debe concurrir; b) el tamaño de las mayorías exigidas para la reforma; y c) la exigencia de la participación popular. Pero la rigidez efectiva depende también del contexto político, histórico, social. Así, menciona como variables relevantes las siguientes: a) el sistema de partidos políticos (cuanto más disciplinados sean los partidos y más arraigada esté la cultura de coalición, tanto más fácil será reformar una constitución); b) el papel simbólico que desempeñe la constitución (por ejemplo, en España la reforma de la Constitución es una especie de tema «tabú»); c) el papel que juegan las tradiciones políticas (es posible que muchas de ellas pueden ser conservadoras, en el sentido de que las razones para proceder a la reforma deban ser de mucho peso); etc. Cfr. Ferreres Comella, Víctor: «Una defensa de la rigidez constitucional», en Doxa, n 23, 2000, págs. 29 y ss.

12 Aquí me interesa simplemente poner de manifiesto el problema (la tensión) que genera la relación entre un poder como el constituyente que en principio está llamado a intervenir en una situación excepcional dando una constitución y un poder soberano -entendido como autodeterminación colectiva- que no se agota jamás y cuya manifestación más importante ad intra del sistema es la potestad legislativa. No voy, sin embargo, a estudiar las diversas propuestas de solución al mismo entre las que pueden destacarse, por ejemplo, la idea schmittiana de que soberano es quien decide en la situación excepcional (Cfr. Estévez Araujo, José A.: La crisis del Estado de Derecho liberal. Schmitt en Weimar, Ariel, Barcelona, 1989, págs 175 y ss.), las que optan por despersonalizar ambos poderes y prefieren hablar de soberanía de la constitución o las que introducen la dualist democracy como forma de superar la tensión entre consti- 
tiene al menos un contenido mínimo que incluye el principio dinámico del sistema jurídico-político de forma que la constitución crea las formas básicas de la acción política y jurídica (órganos y procedimientos), pues como es sabido la acción política en el marco del Estado no es acción natural o amorfa, sino acción institucional.

Este concepto de constitución formal es compatible con el concepto positivista de constitución pero entre ellos hay una diferencia capital. La constitución formal pretende cumplir funciones normativas ex ante, pretende fundar o refundar (hacia el futuro) la identificación, la unidad y la permanencia (la estabilidad en definitiva) de un sistema jurídico-político y lo hace determinando qué va a contar (hacia el futuro) como fundamental en ese sistema. De ahí no se sigue, sin embargo, que transcurrido el tiempo ella opere de hecho como la constitución (en el sentido positivista de la expresión) de la comunidad de referencia. En este sentido, el éxito de una constitución formal se medirá ex post en función de que ella sea el factor principal en la explicación de la estabilización de la conducta jurídica y política de esa comunidad, en definitiva de su unidad y permanencia. Es decir, se medirá por su eficacia, por su capacidad de estabilizar la conducta social, por ser de hecho orden de la conducta. Si bien se considera, la famosa clasificación de las constituciones de Loewenstein que distinguía entre constituciones normativas (se practican), nominales (aspiran a ser practicadas) y semánticas (no se practican en absoluto) puede usarse para clasificar a las comunidades políticas que cuentan con una constitución formal en función de que la constitución opere ex post como el factor determinante, relevante o irrelevante en la explicación de la unidad y la dinámica política de esa comunidad $^{13}$. Es decir, el éxito de una constitución formal se determinará en función de que ella sea practicada en el sentido positivista de la expresión.

tución y democracia, entre constituyente y soberano (Akerman, Bruce: We the People. Foundations, Harvard University Press, 1991, págs. 266 y ss).

${ }^{13}$ Como puede observarse hago un uso un tanto libre de la clasificación «ontológica» de Loewenstein. Su «punto de partida es la tesis de que una constitución escrita no funciona por sí misma [...] sino que una constitución es lo que los detentadores y los destinatarios del poder hacen de ella en la práctica [...] Solamente en este caso cabe hablar de constitución normativa: sus normas dominan el proceso político o, a la inversa, el proceso del poder se adapta a las normas de la constitución y se somete a ellas». Las constituciones son nominales cuando «la situación, de hecho, impide, o no permite por ahora la completa integración de las normas constitucionales en la dinámica de la vida política [...] La función primaria de la constitución nominal es educativa; su objetivo es, en un futuro más o menos lejano, convertirse en una constitución normativa y determinar realmente la dinámica del proceso del poder en lugar de estar sometida a ella». Y finalmente la noción de constitución semántica se refiere a aquellas situaciones en las que «si no hubiese en absoluto ninguna constitución formal, el desarrollo fáctico del proceso del poder no sería notablemente diferente». Cfr. Loewenstein, Karl: Teoría de la Constitución (trad. de A. Gallego), reimpresión de la 2a ed., Barcelona, 1982, págs. 216- 219. 
Esta clasificación, en realidad, no es más que el producto del cruce del concepto de constitución formal con el concepto positivista de constitución.

\subsubsection{La constitución del constitucionalismo político}

La otra gran fuente de contingencia constitucional son los ideales del constitucionalismo político. Es un lugar común considerar que dichos ideales quedaron plasmados en el art. 16 de la Declaración francesa de los derechos al establecer que «una sociedad en la que la garantía de los derechos no está asegurada, ni la separación de poderes está determinada, no tiene una constitución». Pero es obvio que esta referencia al art. 16 no nos resuelve el problema de la determinación de dichos ideales y es obvio también que aquí no puedo detenerme mucho en ello: tenga en cuenta el lector que muchas veces se ha dicho que estos ideales coinciden con los del liberalismo democrático ${ }^{14}$ y que, en este sentido, es obvio que gran parte de la discusión en la filosofía política y el Derecho constitucional de la modernidad ha versado sobre ellos. Ahora bien, en mi opinión, la clave para entender el constitucionalismo político es verlo como una ideología que ha pretendido una determinada configuración del poder político y el aseguramiento del respeto de los derechos; y, en este sentido, la constitución del constitucionalismo tiene que tener necesariamente un fuerte componente de liberación política, es decir, de erradicación de los males más característicos de las dominaciones políticas (o, si no, no es constitución) ${ }^{15}$. Aquí no puedo detenerme mucho en ello, pero piénsese simplemente que si la idealidad del Estado de Derecho, la del Estado liberal, la del Estado democrático y la del Estado social se consideran componentes agregados al constitucionalismo, es fácil darse cuenta de que el sentido de los mismos es respectivamente erradicar los males más característicos (y probados) de las dominaciones políticas: la arbitrariedad, el autoritarismo, la exclusión política

${ }^{14}$ Nino, Carlos Santiago: Fundamentos de Derecho constitucional. Análisis filosófico, jurídico y politológico de la práctica constitucional, Astrea-Depalma, Buenos Aires, 1992, pág. 4.

${ }^{15}$ La idea de fondo es que el esclarecimiento del constitucionalismo como ideológía es inseparable de la denuncia del pseudoconstitucionalismo. En este sentido, por ejemplo, me parece obvia la contradicción presente en la obra de Lassalle [Lassalle, Ferdinand: ¿Qué es una constitución?, (Trad. de Wenceslao Roces), Ariel, Barcelona, 1984] puesto que, por un lado, opera con un concepto de constitución que acaba por ser una mera función del poder político efectivo (es poder desnudo) y, por otro, califica al pseudoconstitucionalismo -entendido como opuesto al constitucionalismo- de mero engaño del despotismo. Esto último sólo es posible, me parece, si se acepta que en la genuina constitución la cuestión primaria no es de poder, sino de valor, de fundamentación. Creo que tiene razón Kay cuando afirma que la función social central de una constitución es prevenir peligros probados [Kay, Richard S.: «Constitutional Chrononomy», en Ratio Juris Vol 13, nº1 mayo 2000, págs. ] y, por tanto, que el constitucionalismo requiere una clara conciencia de ciertos males potenciales de los sistemas políticos. 
y la exclusión social. En efecto, el Estado de Derecho entendido como imperio de la ley o gobierno de las leyes implica una relación de sujeción pero sólo a la voluntad del soberano expresada en normas generales; y ello se traduce en un conjunto de derechos - los propios del Estado de Derechodestinados a erradicar la arbitrariedad en esa relación ${ }^{16}$. El componente liberal del constitucionalismo puede explicarse en términos de la transformación de la relación entre un soberano omnipotente y un súbdito sujeto en la relación entre un soberano competente/incompetente y un ciudadano sujeto/inmune; ése es el papel que tantas veces se ha atribuido a los derechos de libertad: generar esferas de inmunidad y, por tanto también, de incompetencia como forma de combatir el autoritarismo. Y, finalmente, el componente democrático y social de las constituciones puede verse como una transformación de la relación de representación de la comunidad que ejerce el soberano, y que siempre (y necesariamente) es una relación parte/todo. Así, la contradicción que en el seno de la comunidad produce la acción política del soberano, y que permite distinguir entre representados (o favorecidos) y excluidos, se transforma en la contradicción entre mayorías y minorías en todos sus sentidos relevantes. Esa transformación se traduce en el reconocimiento de los derechos de participación política y de igualdad como forma de combatir la exclusión política y social. Obviamente cuáles sean todos esos derechos, cómo se armonicen entre sí y qué papel deban desempeñar no es algo de lo que ahora me pueda ocupar. Lo interesante aquí es

\footnotetext{
${ }^{16}$ En este punto conviene introducir algunas aclaraciones en torno a la noción de «Estado de Derecho». En primer lugar, el concepto de Estado de Derecho es un concepto normativo y, por tanto, con él no se alude simplemente a una mera propiedad descriptiva del Derecho moderno; el Estado de Derecho no nace de la misma juridicidad. En consecuencia, se usa siempre como un concepto normativo, como una exigencia ético-política para evaluar los sistemas jurídicos positivos (Cfr. Laporta, Francisco: «Imperio de la ley. Reflexiones sobre un punto de partida de Elías Díaz», en Doxa, n 15-16 Vol. I, 1994, págs. 1994). Ahora bien, dentro de este uso normativo hay, por decirlo de algún modo, dos formas de entenderlo, según se tome como propiedad principal para su caracterización la idea de imperio de la ley (entendido como un conjunto exigencias éticas que se concretan en características jurídico-formales del orden jurídico y que son condición de posibilidad de la autonomía o la libertad personal) o la de reconocimiento de ciertos derechos sustantivos. La cuestión es de prioridad, no de exclusión. La expresión «Estado de Derecho» usada en ambos sentidos puede coincidir también con dos sentidos de la expresión «Estado constitucional»; así, por ejemplo, cuando Nino distingue entre «constitucionalismo mínimo» y «constitucionalismo pleno» se está refiriendo respectivamente a esas dos versiones del Estado de Derecho [Cfr. Nino, Carlos S.: Fundamentos de Derecho constitucional, Astrea-Depalma, Buenos Aires, 1992, págs. 2-3.]. La necesidad de romper esta ambigüedad está presente también en Ferrajoli cuando distingue entre lo que llama la «mera legalidad» y la «estricta legalidad» [Ferrajoli, Luigi: Derechos y garantías. La ley del más débil, Trotta, Madrid, 1999, págs. 67 y 68]. Aquí uso la expresión «Estado de Derecho» en sentido normativo o valorativo (de forma que no todos los sistemas jurídico-positivos son Estados de Derecho) y en el de «imperio de la ley» o gobierno de las leyes (frente a gobierno de los hombres).
} 
darse cuenta de que no todos los sistemas jurídico-políticos estables satisfacen dichos ideales (exigencias normativas) y que, en consecuencia, no cuentan con una constitución en este sentido.

En este punto, podemos preguntarnos por las relaciones entre la noción de constitución formal y la de constitución del constitucionalismo. Una primera cuestión que parece que hay que aclarar es si el constitucionalismo como ideología exige que se produzca una «legalización de toda acción de gobierno» ${ }^{17} \mathrm{y}$, por tanto, exige la forma constitucional como opuesta a la forma legal ordinaria; o si, por el contrario, exige simplemente que dichos ideales sean practicados aunque no hayan sido «legalizados» $\mathrm{o}$ «codificados» en una constitución formal. Esta discusión, sin duda, da para mucho pero en relación con ella me interesa tan sólo decir lo siguiente: si se acepta grosso modo que, como decía Nino, los ideales del constitucionalismo coinciden básicamente con los del liberalismo democrático, entonces parece razonable afirmar que la constitución formal no es necesaria para su realización y que desde luego tampoco es suficiente. Para mostrarlo conviene introducir la distinción entre «tener una constitución» y «vivir en constitución» ${ }^{18}$ : un sistema jurídico-político «tiene una constitución» cuando cuenta con la forma constitucional como garantía de dichos ideales; y «vive en constitución» cuando esos ideales son practicados. La metáfora de la que nos habla Nino de la «constitución como carta de navegación de un país» ${ }^{19}$ muestra muy plásticamente la aspiración consistente en «darse o tener una constitución» para «llegar a vivir en constitución». Si tomamos en cuenta esto, entonces parece que el caso del Reino Unido ilustra claramente la tesis de que la constitución formal no es necesaria para la vigencia de los ideales del liberalismo democrático, es decir, que es posible «vivir en constitución» sin «tener una constitución» ${ }^{20}$. Y, como es obvio, «tener una constitución», por

\footnotetext{
${ }^{17}$ Bobbio, Norberto: El futuro de la democracia, Plaza y Janés, Barcelona, 1985, pag. 203.

18 Pablo Lucas Verdú [en Teoría de la Constitución como ciencia cultural, Dykinson, 1997, págs. 43 y ss] distingue entre «tener una constitución» y «estar en constitución».

${ }^{19}$ Nino, Carlos Santiago: Fundamentos de Derecho constitucional..., ob. cit. pág. 1

${ }^{20}$ En los últimos tiempos Jeremy Waldron se ha erigido en uno de los principales críticos del constitucionalismo. Su planteamiento consiste en realizar una crítica general al constitucionalismo (entendiendo por tal un movimiento filosófico-político que propugna la forma constitucional) y a la judicial review en particular. Básicamente sostiene que la cuestión política central es la de quién toma las decisiones; y la filosofía política debe construir teorías de la autoridad, más que teorías de la justicia. Conforme a ello sostendrá que la democracia es la teoría de la autoridad más justificada y, en consecuencia, afirmará que no tiene sentido instaurar mecanismos institucionales que le pongan límites; y eso precisamente es lo que hace el constitucionalismo. En este sentido, se opone incluso al «gambito» procedimentalista, es decir, a la constitucionalización del procedimiento. Cfr. Waldron, Jeremy: «A Rights-Based Critique of Constitutional Rights», en Oxford Journal of Legal Studies, vol 13, n¹, págs. 18-51.
} 
más que en ella se hayan plasmado esos ideales, no es suficiente para afirmar que una comunidad «vive en constitución». La prueba de ello es, como antes dijimos, la necesidad que la teoría constitucional ha tenido de distinguir entre las constituciones formales que se cumplen (se practican) y las que no.

Ahora bien, más allá de la coincidencia de valores y fines entre el liberalismo democrático y el constitucionalismo como ideología, este último puede definirse como aquella ideología política que ha propugnado «darse una constitución» (una constitución rígida o formal) como garantía de «vivir en constitución» (de la práctica de esos ideales). Si se recuerda, al introducir la noción de constitución formal he dicho que ésta tiene que tener al menos un contenido mínimo que incorpore el principio dinámico del sistema jurídico-político. De manera que la constitución tiene que crear (constituir) las formas básicas de la acción política y jurídica (es decir, crear los órganos y procedimientos básicos), pues la acción política y jurídica en el marco del Estado no es una acción natural -o amorfa-, sino institucional. Pues bien, lo que me interesa ahora es mostrar que la constitución formal del constitucionalismo no sólo «crea» cosas, sino que también «reconoce» cosas; o lo que es lo mismo, además de una dimensión constitutiva tiene una dimensión valorativa. Tratemos de explicarlo.

La dimensión constitutiva de toda constitución es obvia: los parlamentos (unicamerales o bicamerales), los tribunales constitucionales, las comunidades autónomas, las elecciones generales, las mayorías cualificadas, etc. son todas ellas realidades institucionales creadas por las constituciones. Ahora bien, las constituciones no sólo tienen esa dimensión constitutiva, no sólo crean órganos y procedimientos, sino que además tienen una dimensión valorativa ${ }^{21}$, reconocen estados de cosas como valiosos y, por tanto,

\footnotetext{
Ahora bien, la tesis de fondo de Waldron -más allá de los múltiples argumentos que despliega- creo que puede reducirse a la afirmación -que, por otro lado, me parece obvia- de que es preferible «vivir en constitución» que «tener una constitución»; ello se muestra con mucha claridad cuando al final de Law and Disagreement viene a sostener que en efecto en algunas nuevas democracias tiene sentido garantizar la libertad (pone el ejemplo de las nuevas democracias del Este de Europa y de la antigua Unión Soviética), pero que ese no es el caso de Estado Unidos ni del Reino Unido, que son países que al tener fuertes tradiciones de libertad política y debates vigorosos pueden proceder sin temor a que se ponga en peligro la libertad de las minorías. Waldron, Jeremy: Law and Disagreement, Clarendon Press, Oxford, 1999, págs.278 y SS.

${ }^{21}$ En este punto tal vez podría objetarse que lo que en realidad se opone (o complementa) a la dimensión constitutiva de las constituciones no es simplemente una dimensión valorativa, sino una dimensión regulativa, de guía de la conducta. Más adelante introduciré algunas precisiones al respecto, pero en este punto me limito a referirme a la dimensión valorativa porque me parece que ninguna concepción de la constitución ha negado esa dimensión, mientras
} 
merecedores de ser protegidos y/o promocionados (es decir, de ser garantizados). La soberanía popular, la independencia de la nación, la libertad, la igualdad, la dignidad y la seguridad de las personas, el pluralismo político, la diversidad cultural, la educación, la salud pública, etc, etc. no son cosas creadas por la constitución (constituidas como valiosas por la constitución), sino reconocidas como valiosas por la constitución ${ }^{22}$. Son aquellos fragmentos de la constitución que permiten interpretar la acción de darse una constitución como una acción racional en el sentido weberiano de la expresión; es decir, «racional con arreglo a fines» (para el logro de fines racionalmente sopesados y perseguidos) y/o «racional con arreglo a valores» (determinada por la creencia consciente en el valor $)^{23}$. En definitiva, las constituciones reconocen valores y fines que dotan de sentido a las formas de acción política (órganos y procedimientos) creadas por ellas mismas.

La aceptación de esta distinción es de una importancia y un alcance extraordinarios para la lectura de las constituciones, porque ella supone que los valores y los fines reconocidos por la constitución nunca son reducibles a las formas de acción política creadas por la propia constitución y, en este sentido, el ritualismo constitucional constituiría una forma de conducta desviada. En efecto, aunque haría falta introducir bastantes precisiones relativas a la distinción entre valores y fines, la idea de reconocimiento de valo-

que -como veremos en seguida- no han sido pocas las concepciones que han negado, ignorado o al menos se han mostrado escépticas en relación con la dimensión regulativa (de imposición de deberes) de las constituciones.

22 Soy perfectamente consciente de las resonancias iusnaturalistas que muchos atribuirán a la expresión «reconocimiento» de valores y fines. Como inmediatamente se verá he recurrido a ella con la pretensión de establecer una prioridad interpretativa de éstos frente a las formas de acción (poder normativo) creadas por la constitución, pero no para abrir una brecha de suprapositividad frente a la constitución formal. En este sentido, he pretendido usar el término «reconocimiento» huyendo de la alternativa que, por ejemplo, formula Riccardo Guastini cuando se pregunta: «¿reconocimiento o creación de derechos? [...] la cuestión es si los derechos enunciados en la declaración son propiamente 'declarados'; es decir, simplemente reconocidos, o por el contrario 'constituidos'; es decir, creados ex novo. Como es claro -dice- la respuesta a esa cuestión depende de una previa adhesión a una determinada filosofía del derecho». Para a continuación añadir: «Los partidarios del iusnaturalismo reiteran que existen 'en la naturaleza' derechos (subjetivos), antecedentes a toda disciplina positiva e independientes de ella: derechos, por lo tanto, que la Constitución se limita a reconocer [..] Por el contrario, los partidarios del positivismo jurídico reiteran que no existen derechos (subjetivos) preexistentes al derecho positivo, y que, por tanto, los derechos en cuestión no son reconocidos, sino creados y adscritos a los ciudadanos originariamente por la Constitución». En Guastini, Riccardo: «¿Peculiaridades de la interpretación constitucional?» (Trad. De Miguel Carbonell), en Guastini, Riccardo: Estudios sobre la interpretación jurídica, Porrúa-UNAM, México, 2000, págs. 125 y 126.

${ }^{23}$ Weber, Max: Economía y sociedad, Fondo de Cultura Económica, México, $10^{a}$ reimp., 1993, pág. 20 
res supone que éstos son «anteriores» a las formas de acción política creadas por la constitución; y la idea de reconocimiento de fines supone que éstos son «externos» a las formas de acción política creadas por la constitución. Lo cual los convierte en un elemento de crítica y valoración de la conducta política efectiva realizada según las formas de acción política creadas por la constitución ${ }^{24}$. Quien entienda lo anterior está en condiciones de entender muchas de las discusiones - no siempre claras- que han acompañado al constitucionalismo político. Desde las discusiones sobre los «derechos prepolíticos» hasta las discusiones sobre cuál es el diseño institucional adecuado para realizar los ideales del constitucionalismo. En cualquier caso, el proceso del constitucionalismo político y la discusión filosófica que lo ha acompañado creo que sólo se entienden si se parte de la distinción entre formas de acción política «constituidas» por la constitución y valores y fines «reconocidos» por la constitución. Obviamente la necesidad de la distinción es independiente de la fortuna en la elección de las palabras.

En definitiva, todo lo anterior trata de mostrar que el sentido de «darse una constitución» es el de fundar o refundar la unidad de una comunidad política asegurando, frente a la política ordinaria, ciertas formas de acción política y ciertos criterios de legitimidad de las mismas, es decir, ciertos valores que la acción política y jurídica tiene que respetar y ciertos fines que la acción política y jurídica tiene que perseguir. Lo anterior me parece que es consustancial a todo el constitucionalismo. Ahora bien, dentro del constitucionalismo como ideología creo que pueden distinguirse algo así como dos grandes grupos de concepciones - que se hallan en una cierta oposiciónrelativas a la eficacia de la constitución, es decir, relativas a cómo hacer efectivos esos valores y fines, a cómo garantizarlos. Por un lado, hay con-

\footnotetext{
${ }^{24}$ Luigi Ferrajoli ha insistido particularmente en la idea de asumir lo que él llama un punto de vista únicamente externo a los fines de la legitimación y de la deslegitimación ético-política del Derecho y del Estado. Así se puede leer: «[...] la adopción de un punto de vista externo o político que no esté calcado sobre el interno o jurídico es el presupuesto de toda doctrina democrática de los poderes del estado [...] En un doble sentido: porque el punto de vista externo es el de abajo o ex parte populi, frente al interno, que es el punto de vista de arriba o ex parte principis; y porque el primero es el que expresa los valores extra -o meta- o pre-jurídicos 'fundamentales', o sea los intereses y las necesidades 'naturales' -individuales y colectivas- cuya satisfacción representa la justificación o razón de ser de esas cosas 'artificiales' que son las instituciones jurídicas y políticas. Mientras, la eliminación de un autónomo punto de vista externo o, peor aún, su explícita confusión con el interno son el rasgo específico de todas las culturas políticas autoritarias, unidas de formas diversas por la idea de la auto-fundamentación y la auto-justificación del derecho y del estado como valores en sí: no medios, sino fines en sí mismos. Añado que la carga de la justificación externa es idónea para fundamentar doctrinas políticas que admiten justificaciones no absolutas o totales, sino contingentes, parciales, a posteriori y condicionadas [...]» Ferrajoli, Luigi: Derecho y razón. Teoría del garantismo penal, Trotta, Madrid, 1997 (2ª ed.), págs. 853-854.
} 
cepciones del constitucionalismo que se muestran escépticas hacia el papel regulativo (de guía de la conducta, de imposición de deberes) que pueda desempeñar la constitución. Estas concepciones tienden a pensar que la eficacia de la constitución (la efectividad de esos valores y fines) depende centralmente de un correcto diseño de las formas de acción jurídica y política y en consecuencia han puesto el énfasis en la dimensión constitutiva de las constituciones: las formas de acción política y jurídica tienen que ser correctas, equilibradas (pesos y contrapesos), compensatorias de pasiones, deliberativamente idóneas, etc. Han puesto el acento en la división de poderes, la inamovilidad de los jueces, la legalidad de la administración, el imperio de la ley, la regla de las mayorías, etc. Frente a estas corrientes, hay otro gran grupo de concepciones que, por el contrario, han pensado que la eficacia de la constitución (es decir, de los valores y fines del constitucionalismo) no depende sólo ni fundamentalmente de las formas de acción política y jurídica creadas por la constitución, que no es una cuestión de diseños institucionales «perfectos» pues la desviación siempre es posible. En consecuencia, han enfatizado la traducción de los valores y los fines en deberes, afirmando una dimensión regulativa de la constitución. De forma que la eficacia de la constitución dependerá centralmente -como ocurre con cualquier norma de conducta- de la adaptación de la conducta y de los controles frente a la desviación. En torno a estas dos actitudes básicas pueden vertebrarse (de forma graduada) muchas de las concepciones constitucionales ${ }^{25}$. Pero en cualquiera de ellas está siempre presente la prioridad de los valores y los fines, de los derechos. El constitucionalismo de los diseños institucionales justifica las diferentes formas de acción jurídica y política creadas por su idoneidad para asegurar los valores y los fines; y el constitucionalismo regulativo no ve los deberes constitucionales como una mera imposición política, sino que los ve en una conexión justificativa con esos valores y fines ${ }^{26}$. Un ejemplo tal vez ayude a entender mejor lo que se quie-

\footnotetext{
${ }^{25}$ Ahora no puedo detenerme a justificarlo, pero me parece que si se toman diferentes pares de concepciones opuestas de la constitución (por ejemplo, la concepción mecánica frente a la normativa, la procedimentalista -en sus diversas versiones- frente a la sustantivista o principialista, la concepción política frente a la jurídica y la concepción de la constitución como fuente de las fuentes del Derecho frente a la de fuente del Derecho) es fácil reconducir dichas oposiciones a la oposición entre el énfasis en la dimensión constitutiva de la constitución frente al énfasis en la dimensión regulativa.

${ }^{26} \mathrm{Si}$ se admite la conexión necesaria entre constitución del constitucionalismo y reconocimiento de derechos de forma que estos cumplen una función de fundamentación, es fácil percatarse de que dentro del constitucionalismo político hay dos grandes corrientes a propósito del papel que deben jugar los derechos. Una viene a sostener que el papel de los derechos es centralmente el de fundamentar las formas legítimas de la acción (poder) jurídico y político (básicamente las formas de acción del Estado de Derecho y las del Estado democrático); la otra
} 
re decir. Pensemos en el principio de independencia judicial que, no cabe duda, está en el centro del constitucionalismo. Si se repasa la literatura relativa a este principio es fácil observar que hay dos grandes formas de abordar la cuestión de la eficacia del mismo. Una pone el acento en el diseño de la posición institucional del juez, de forma que la eficacia del principio parece ser una variable dependiente de factores tales como la inamovilidad, la predeterminación, el autogobierno, la remuneración, la no asociación política, etc. Otra, sin embargo, interpreta centralmente el principio como un deber de independencia del juez que se traduce en la exigibilidad de ciertas actitudes con independencia del marco institucional en el que realice su función (aunque éste obviamente pueda facilitar o dificultar su cumplimiento). Como se ve, la oposición no es una cuestión de todo o nada, más bien es de acentos y prioridades ${ }^{27}$.

Pero no nos distraigamos más con el constitucionalismo y centrémonos ahora en el papel que la constitución juega como fuente del Derecho en el llamado Estado constitucional.

\section{La constitución de los Estados constitucionales}

¿A qué nos referimos cuando hablamos de Estados constitucionales? Una respuesta fácil (pero inútil) consistiría en afirmar que Estado constitucional es aquel que cuenta con una constitución; a estas alturas, sin embargo, la inutilidad de la misma ya es palmaria. Para usar de manera relevante la expresión «Estado constitucional» deben, me parece, tomarse en cuenta los tres sentidos de constitución antes destacados. Así, de manera tentativa, puede decirse que cuando hablamos de Estados constitucionales aludimos a sistemas jurídico-políticos que reúnen las siguientes características.

1. Son sistemas que cuentan con una constitución rígida o formal, es decir, con una constitución diferenciada de la forma legal ordinaria. Ello supone necesariamente que el régimen jurídico de las disposiciones constitucionales es diferente y superior al de las disposiciones legales. Por tanto, desde la perspectiva interna de la doctrina de las fuentes del Derecho, los Estados constitucionales se caracterizan por contar con una constitución formal y ello implica siempre -como mínimo- una diferencia de grado en relación con las otras fuentes del Derecho. Del mismo modo que pueden observarse diferencias de grado entre ley y reglamento (grado de generalidad

considera que la función de los derechos es fundamentar los límites normativos al poder político y jurídico (y, en consecuencia, enfatizan un sustantivismo vinculado al Estado liberal y al Estado social).

${ }^{27}$ Cfr. Aguiló Regla, J.: «Independencia e imparcialidad de los jueces y argumentación jurídica», en Isonomía, nº 6, abril 1997. 
y abstracción, relación de dependencia tanto de la validez constitutiva como de la regulativa, mayor estabilidad de la ley que del reglamento, etc.), pueden detectarse entre la constitución formal y la ley ordinaria. La supralegalidad de la constitución formal implica una ampliación de la doctrina de las fuentes, pero en principio no mucho más.

2. Dicha constitución responde a las pretensiones normativas del constitucionalismo político: la limitación del poder político y la garantía de los derechos; es decir, asume los valores y fines del constitucionalismo como ideología. En este sentido, la constitución formal del Estado constitucional no puede incorporar sólo - como diría Kelsen- el principio dinámico del Estado. No puede tener sólo como función la de hacer posible el ejercicio institucionalizado del poder político; sino la de hacer posible un poder político institucionalizado desde ciertos valores y fines asumidos. En este sentido, las constituciones formales de los Estados constitucionales han incorporado las dos grandes estrategias del constitucionalismo político: la de los diseños institucionales idóneos para la garantía de esos valores y fines y la del carácter regulativo de esos valores y fines. Se trata, pues, de constituciones constitutivas y regulativas. Así, incorporan las formas básicas de la acción jurídica y política que desde el constitucionalismo se consideran legítimas, es decir, idóneas para asegurar los valores y fines reconocidos: básicamente han incorporado las formas de acción jurídica propias del Estado de Derecho y los derechos que las acompañan (están comprometidas con la erradicación de la arbitrariedad) y las formas de acción política propias del Estado democrático y los derechos que las acompañan (están comprometidas con la erradicación de la exclusión política). Pero, también, la constitución del Estado constitucional ha seguido la estrategia del constitucionalismo regulativo, de modo que sus valores y fines se han incorporado a la constitución en la forma de principios regulativos de la acción política legítima. Así, las constituciones han incorporado los derechos y principios liberales (están comprometidas con la erradicación del autoritaritarismo) y los derechos y principios del Estado social (están comprometidas con la erradicación de la exclusión social). Todos estos elementos, en mayor o menor medida, son reconocibles, me parece, en las constituciones de los Estados que llamamos constitucionales. Ahora bien, si como traté de mostrar antes, la asunción ideológica del constitucionalismo presupone la consideración de que los valores son anteriores a las formas de acción jurídica y política constituidas (creadas) por la constitución y los fines son externos a las mismas, entonces el uso de la constitución como fuente del Derecho desde estos parámetros tiene que reflejar dicha prioridad axiológica y justificati- 
va. Prioridad que se plasmará en los juicios normativos internos, en los juicios de validez, en las operaciones del método jurídico, etc. ${ }^{28}$

3. La constitución formal que responde a los parámetros normativos del constitucionalismo además tiene que ser practicada. En efecto, para hablar de Estado constitucional la constitución formal debe ser aceptada como conteniendo el conjunto de normas fundamentales de ese sistema jurídico y político. En otras palabras, para hablar de Estado constitucional tiene que haberse consolidado una práctica jurídica y política que permita afirmar que de hecho en torno a la constitución formal se ha producido la estabilización de las conductas jurídicas y políticas de la comunidad de referencia, de forma que ella pueda ser considerada como norma fundamental y, en consecuencia, jugar su papel en relación con los problemas de identificación, de unidad y de continuidad del sistema jurídico-político. Es decir, para hablar de Estado constitucional la constitución formal del constitucionalismo tiene que ser positiva, tiene que ser usada desde los parámetros del constitucionalismo.

Llegados a este punto, conviene poner de manifiesto los límites del concepto de constitución. En realidad, lo anterior nos permite distinguir entre los sistemas jurídico-políticos que pueden ser considerados Estados constitucionales y los que no. Es decir, nos permite aislar unos sistemas de otros, pero poco más. Ciertamente no nos aclara demasiado el papel que la constitución juega como fuente del Derecho. Si se recuerda, antes dije que la peculiaridad central de la constitución como fuente del Derecho desde los parámetros del normativismo radicaba en que ella opera como el punto de conexión entre el problema interno y el problema externo de la teoría de las fuentes, que ello la convertía en un núcleo central de la teoría del Derecho y que, en este sentido, no podía haber mucha distancia entre la discusión sobre el concepto y la naturaleza del Derecho y la discusión sobre el concepto y la naturaleza de la constitución. Pues bien, no hace mucho leí una frase que me parece que resume muy bien lo que trato de decir: «El problema del Derecho constitucional es que nadie sabe qué cuenta como un argu-

\footnotetext{
${ }^{28}$ Como es sabido, la filosofía política se debate entre la teoría de la autoridad legítima y la teoría de la justicia. Dentro del constitucionalismo, esta tensión se muestra en el debate sobre la prioridad entre las formas institucionales de la acción política legítima (los procedimientos correctos: básicamente los del Estado de Derecho y los del Estado democrático) y los deberes prescritos (las sustancias que deben protegerse y promocionarse: básicamente las del Estado liberal y las del Estado social). Tanto unas como otros (las formas de acción institucional y los deberes prescritos) son el resultado de compromisos éticos básicos y, en este sentido, presentan la prioridad axiológica a la que he venido aludiendo. La cuestión difícil y de fondo es cómo se articulan entre sí unos y otros principios constitucionales.
} 
mento ${ }^{29}$. La idoneidad de la frase radica en que expresa con claridad los límites del concepto de constitución; aunque probablemente sea exagerada, porque una cosa es no saber qué cuenta como el mejor argumento y otra, qué cuenta como un argumento. Lo primero puede ser cierto, pero lo segundo claramente no lo es: es perfectamente posible aislar las diferentes concepciones relevantes y rivales. Antes dije que las prácticas jurídicas y políticas nunca eran tan homogéneas como para poder ser descritas sin más y en consecuencia poder ser usadas normativamente «como si». Ello en el ámbito constitucional es más radical si cabe: la operatividad de las constituciones formales pende directamente de las concepciones constitucionales. Ello es así porque la armonización normativa y operativa de las propiedades de las constituciones exige centralmente justificación, no descripción. Las concepciones constitucionales suministran criterios para la interpretación y aplicación de las constituciones y en este sentido aparentemente se produce una cierta confusión entre las concepciones constitucionales y las propiedades de las constituciones; pero estas últimas son susceptibles de ser descritas, aquéllas requieren justificación: obviamente no es lo mismo afirmar que nuestra constitución es una constitución democrática que proponer una lectura democrática de la constitución. Las disputas entre concepciones constitucionales no versan sobre las propiedades que caracterizan a una constitución, sino sobre la preeminencia (la ordenación) de unas sobre otras.

\section{Dos concepciones de la constitución como fuente del Derecho o dos modelos de relación entre constitución regulativa y orden jurídico. De los derechos frente al Estado a la constitucionalización del orden jurídico}

A continuación trataré de exponer dos modelos opuestos relativos al papel que la constitución regulativa juega como fuente del Derecho dentro del Estado constitucional. Estos modelos responden a concepciones diferentes del Derecho y de la constitución y tienen su reflejo dentro de la teoría del Derecho. La clave para entender la cuestión está en cómo interpretar los deberes incorporados en las normas constitucionales regulativas, es decir, en cómo interpretar la dimensión regulativa de la constitución. Según un modelo, la constitución opera centralmente como un límite respecto del resto del orden jurídico; según el otro, el orden jurídico es un desarrollo de las

\footnotetext{
${ }^{29}$ Gerhardt, Michael J. y Rowe, Thomas D.: Constitutional Theory: Arguments and Perspectives, Charlottesville, VA: Michie Company, 1993, pág.1; citado por Cooter, Robert D.: The Strategic Constitution, Princeton University Press, Princeton, New Jersey, 2000, pág. 1.
} 
exigencias regulativas de la constitución. Naturalmente, todas las constituciones pueden contener normas cerradas que imponen límites y normas abiertas que requieren desarrollo, pero eso es algo obvio que ahora no nos interesa. Lo relevante es mostrar que dentro del constitucionalismo y de los Estados constitucionales se ha producido una cierta evolución que ha consistido en pasar de interpretar los derechos y los principios constitucionales como exigencias que centralmente imponen límites negativos a la acción política y jurídica legítimas a verlos como el contenido propio de la acción política y jurídica legítimas. Y ello ha tenido su reflejo en la teoría jurídica que ha pasado de establecer una conexión externa entre derechos constitucionales y orden jurídico a establecer entre ellos una conexión interna. La mejor manera de mostrar esa evolución probablemente sea explicar los dos modelos de relación entre derechos constitucionales y orden jurídico.

El modelo de la conexión externa concebirá los derechos constitucionales centralmente como límites negativos al contenido del orden jurídico, limites negativos a la acción del Estado (a la soberanía del Estado y a la acción política legitima). La legitimidad del orden jurídico dependerá fundamentalmente del «respeto» a dichos límites, a los derechos. Las exigencias normativas en términos de «límites» $\mathrm{y}$ «respeto» responden a la cuestión de qué no se puede ordenar, prohibir o sancionar legítimamente. Frente a él, el modelo de la conexión interna concebirá el orden jurídico básicamente como un desarrollo positivo de los derechos fundamentales, el contenido del orden jurídico será una concreción de las exigencias normativas derivadas de los derechos constitucionales. Se otorgará a los derechos constitucionales una fuerza expansiva fundamental en la determinación del contenido del orden jurídico. Las exigencias normativas derivadas de los derechos constitucionales ya no se verán como límites negativos y deberes de respeto, sino como exigencias de «desarrollo»y «concreción» de los mismos: ellos serán la fuente central para determinar qué se debe ordenar, prohibir y sancionar. Esta evolución tal vez podría resumirse en la fórmula «de la consideración de la constitución como límite al orden jurídico a la consideración del orden jurídico como un desarrollo de las exigencias constitucionales».

Estas dos formas de concebir el papel de los derechos constitucionales están hoy en el centro de la discusión constitucional y tienen una honda repercusión dentro de la teoría jurídica, pues es fácil mostrar su trascendencia para la concepción del Derecho y del método jurídico. Conforme al modelo del respeto de los derechos, el orden jurídico tiene un contenido relativamente autónomo en relación con la constitución. Los derechos son límites negativos al contenido del orden jurídico y a la acción política del Estado; en consecuencia, el control normativo que desempeña la constitución como fuente es un control negativo. La inconstitucionalidad puede canalizarse a 
través de los principios de jerarquía y de inconsistencia normativas, esto es, a partir de la contradicción entre la normativa constitucional y la normativa jurídica. El contenido legítimo del orden jurídico es explicable a partir de una combinación de respeto a los derechos y discrecionalidad (entendida como libertad dentro de los límites establecidos por aquellos).

Pero hay otra forma de entender las relaciones entre constitución y orden jurídico; o mejor, entre derechos constitucionales y orden jurídico. Aquí el contenido del orden jurídico carecerá de autonomía en relación con las normas constitucionales. Estas normas regularán no sólo las relaciones de los ciudadanos con el Estado, sino también las relaciones entre los ciudadanos. El orden jurídico legítimo ya no será aquel que simplemente respeta los derechos, sino aquel que desarrolla en positivo todas las exigencias normativas derivadas de los derechos. El contenido del orden jurídico legítimo ya no resultará explicable en términos de respeto de los límites y discrecionalidad entendida como libertad; sino en términos de una concreción de los derechos a partir de una «razonable» ponderación de bienes y principios constitucionales; de forma que la discrecionalidad no podrá interpretarse ya como ausencia de guía normativa, sino más bien como ese tipo específico de deberes que denominamos «responsabilidades». En consecuencia, el control normativo que la constitución como fuente del Derecho ejerce en relación con el orden jurídico es mucho más expansivo. Las relaciones entre constitución regulativa y orden jurídico ya no se presentan en términos de una oposición en forma de límites; y, por tanto, los principios de consistencia y jerarquía normativas ya no serán suficientes para dar cuenta del rol normativo de la constitución, ni del método y el razonamiento jurídicos. El orden jurídico legítimo será expresivo de una «razonable» determinación y concreción de los derechos constitucionales; y de esta forma, junto a la exigencia de consistencia normativa por lo que se refiere a la unidad de contenidos del orden jurídico, hará aparición la exigencia de coherencia valorativa como test de corrección normativa. La noción de laguna normativa será desplazada por la de laguna axiológica y la de caso difícil, pues de la constatación de la falta de regulación (o de regulación defectuosa) se procederá a buscar en las fuentes constitucionales la respuesta correcta en relación con el caso en cuestión. Todo ello ha desembocado en lo que se ha venido en llamar «la constitucionalización del orden jurídico» ${ }^{30}$ y ha supuesto que en la teoría del Derecho se haya producido un desplazamiento desde la teoría de la autoridad a la teoría de la justicia.

30 Cfr. Guastini, Riccardo: «La 'costituzionalizzazione' dell'ordinamento italiano», en Ragion Pratica, nº 11 1998, págs. 185 y ss. 
Estos dos modelos me parece que son fácilmente reconocibles para todos aquellos que estén familiarizados con la teoría del Derecho; en realidad, tiene mucho que ver con la proyección al nivel constitucional de la confrontación entre el modelo de las reglas y el modelo de los principios en la concepción general del Derecho y del método jurídico. Pero en cualquier caso, estos dos modelos no valen para clasificar constituciones; no es posible realizar afirmaciones tales como, por ejemplo, que nuestra constitución responde al primero o al segundo de los modelos. Obviamente podrá reconocerse que la jurisprudencia actual de un tribunal constitucional y respecto de cierta materia se adapta más a uno que a otro; pero no valen para clasificar constituciones porque, en realidad, esos dos modelos no responden a rasgos estructurales (formales) de los sistemas constitucionales, sino más bien a rasgos de la cultura jurídica predominante en un sistema constitucional. La identificación mayor o menor con cada uno de los modelos será una función de la concepción constitucional dominante en la cultura jurídica de referencia, es decir, de la constitución como práctica. Es más, probablemente pueda observarse que dentro de un mismo sistema constitucional puede describirse una evolución desde el primero hacia el segundo de los modelos. En este sentido, no me resisto a reproducir por extenso unas palabras de Guastini críticas en relación con esta evolución pero que me parecen extraordinariamente representativas de la oposición entre estos dos modelos de teoría del Derecho. Escribe Guastini a propósito de lo que llama «el principio de razonabilidad» y «la máquina de fabricar lagunas»:

«En muchos sistemas constitucionales contemporáneos, el límite sustancial a la legislación más importante es el llamado principio de 'razonabilidad' [...] Se trata de un principio elaborado por diversos tribunales constitucionales a partir de la interpretación de las disposiciones [...] que establecen el principio de igualdad, es decir, la prohibición al legislador de distinguir (o discriminar) entre ciudadanos [...] En muchas constituciones el principio está formulado como una regla específica, que prohíbe no cualquier distinción [...] sino algunas particulares y determinadas: raza, sexo, opiniones políticas, etc. Por tanto, hay ciertas distinciones que están prohibidas [...] mientras que otras están permitidas [...] Sin embargo, diversos tribunales entienden el principio de igualdad como un principio genérico del tipo: 'los casos iguales deben ser tratados del mismo modo y los casos diferentes deben ser tratados de modos diferentes'. Este principio, así formulado, plantea el problema de decidir qué casos son iguales y cuáles no: dicho de otro modo, qué distinciones están justificadas y cuáles son discriminatorias. El principio de razonabilidad es precisamente una respuesta a esta pregunta. Desgraciadamente es una respuesta tautológica [...] según el principio de razonabilidad, una distinción está justificada cuando está justificada [...] En las manos de los tribunales constitucionales esta interpretación del principio de igualdad se convierte en un instrumento muy potente para revisar discrecionalmente las decisiones discrecionales del legislador. 
«[...] Se llama 'laguna axiológica' a la falta no de una norma cualquiera, sino de una norma 'justa', es decir, de una norma que no está pero que 'debería' estar, porque es requerida por el sentido de justicia del intérprete o por una norma superior. El principio de igualdad, interpretado como principio de razonabilidad, es una fuente de lagunas axiológicas: podría decirse que es una máquina para producir lagunas [...] Cuando el legislador trata de modo diverso casos que al intérprete le parecen iguales [...], entonces el intérprete dirá que falta una norma igualadora. Cuando por el contrario el legislador trata en modo igual casos que al intérprete le parecen diferentes [...], entonces el intérprete sostendrá que falta una norma diferenciadora $»^{31}$

Pues bien, para acabar, me interesa simplemente llamar la atención sobre lo siguiente: si es cierto que se ha producido dicha evolución y que ella no es explicable en términos de cambios estructurales o formales de los sistemas constitucionales, porque no es el producto de ninguna reforma o modificación de la constitución (del texto constitucional) sino que ella más bien es producto de un cambio de concepción constitucional dominante, es decir, de la interpretación de la propia práctica constitucional, del sentido atribuido a la constitución y a la práctica constitucional, entonces quien acepte las tesis positivistas de las fuentes sociales del Derecho tendrá que revisar la imagen interna del sistema jurídico construida a partir de un sistema de autoridades y una oposición fuerte entre los procesos de creación y aplicación del Derecho. Como es sabido, en los últimos tiempos se ha escrito mucho a propósito de si el constitucionalismo contemporáneo (rígido, regulativo y abierto) habría hecho entrar en crisis al positivismo jurídico; pues bien, mi opinión es que la tesis de las fuentes sociales del Derecho permanece inalterable: el Derecho o es orden de la conducta social o no es Derecho. Lo que ocurre es que esta tesis no da para vertebrar un movimiento porque en realidad nadie la niega. Lo que sí me parece que entra en crisis son las imágenes centralmente autoritativas del Derecho que han enfatizado mucho la oposición entre los procesos de creación y los procesos de aplicación del Derecho; y entran en crisis precisamente porque, como he tratado de mostrar, no son sustentables a partir de las tesis empiristas del positivismo. Esas imágenes del Derecho son el producto de esquemas conceptuales creados para dar cuenta de un modelo histórico del Derecho que la evolución política de nuestras sociedades está dejando atrás. En realidad, hoy en día, la insistencia en las mismas creo que poco tiene que ver con los presupuestos empiristas del positivismo, sino que más bien es el producto de ciertas tesis filosóficas vinculadas al escepticismo y al relativismo en el ámbito de la razón práctica.

${ }^{31}$ Guastini, Riccardo: «La costituzione come limite alla legislazione», en Analisi e diritto, 1998 , págs. 111 y 112 . 
$\triangle \quad$ DOXA 24 (2001) 